\title{
Lead and Chromium Immobilization Process Subjected to Different Freeze-Thaw Treatments in Soils of the Northeastern Qinghai-Tibet Plateau
}

\author{
Leiming $\mathrm{Li}^{1}$ and Jun $\mathrm{Wu} \mathbb{B D}^{1,2}$ \\ ${ }^{1}$ Key Laboratory of Comprehensive and Highly Efficient Utilization of Salt Lake Resources, Qinghai Institute of Salt Lakes, \\ Chinese Academy of Sciences, Xining, Qinghai 810008, China \\ ${ }^{2}$ School of Resources and Environmental Engineering, Ludong University, Yantai, Shandong 264025, China
}

Correspondence should be addressed to Jun Wu; wujunlisa@163.com

Received 3 August 2021; Revised 17 September 2021; Accepted 7 October 2021; Published 21 October 2021

Academic Editor: Peng Zhang

Copyright (c) 2021 Leiming Li and Jun Wu. This is an open access article distributed under the Creative Commons Attribution License, which permits unrestricted use, distribution, and reproduction in any medium, provided the original work is properly cited.

\begin{abstract}
The freeze-thaw cycle is one of the important processes that affected heavy metal behaviors in soil. However, information regarding the adsorption and desorption behavior of heavy metals in soils under different freeze-thaw conditions is relatively less. Therefore, different freeze-thaw conditions including unfrozen, 15 freeze-thaw cycles at $60 \%$ water content, and 15 freeze-thaw cycles at $100 \%$ water content were investigated. Then the adsorption and desorption behaviors of $\mathrm{Pb}$ and $\mathrm{Cr}$ in freeze-thaw soils were studied. Results showed the $\mathrm{Pb}$ and $\mathrm{Cr}$ adsorption amount mostly decreased with increasing water-soil ratio, and the soil performance of $\mathrm{Pb}$ and $\mathrm{Cr}$ adsorption at same water-soil ratios showed variation under different freeze-thaw conditions. The $\mathrm{Pb}$ isothermal adsorption was higher for most freeze-thaw treatments compared to the control. The soil performance of $\mathrm{Cr}$ isothermal adsorption showed variation under different freeze-thaw conditions. Most electrostatic binding of $\mathrm{Pb}$ and $\mathrm{Cr}$ were stronger under unfrozen and freeze-thaw conditions than unfrozen conditions. Most $\mathrm{Pb}$ and $\mathrm{Cr}$ adsorption kinetics patterns of freeze-thaw treated soils were rapid than unfrozen conditions. These results implied that freeze-thaw cycles could change the soil adsorption and desorption patterns of $\mathrm{Pb}$ and $\mathrm{Cr}$. Therefore, further studies are urgently needed to investigate $\mathrm{Pb}$ and $\mathrm{Cr}$ immobilization mechanisms in soils during freeze-thaw cycles. Hence, these findings provided useful information on $\mathrm{Pb}$ and $\mathrm{Cr}$ immobilization process in soils that underwent freeze-thaw cycles to offer an additional insight into predicting $\mathrm{Pb}$ and $\mathrm{Cr}$ behaviors in cold and freezing environments.
\end{abstract}

\section{Introduction}

The soil freeze-thaw cycle (FTC) is a common natural phenomenon in the high- and middle-latitude regions of the northern hemisphere; the Qinghai-Tibet Plateau is located in the temperate zone with an alpine climate [1]. Significant effects of freeze-thaw cycles on soil characteristics have been widely reported [2-4]. For example, freeze-thaw cycles (FTCs) can significantly alter soil aggregate stability and density $[5,6]$. Soil community structures, microbial activities, and extractable $\mathrm{N}$ concentration are also affected by FTCs [7-10]. Organic mineralization can also be affected by FTCs [11]. Multiple freeze-thaw treatments (FT-treatments) also caused a significant increase in the release of dissolved organic carbon [12]. However, different experiment results have been found. The methodological differences in FTC experiments in different soils cause the different research results. Large FTC amplitudes and rapid FTC rates are reported to produce large effects on soil properties, whereas moderate FTC amplitudes and slow FTC rates have minimal effects $[13,14]$. Additionally, the freezethaw time also differs significantly among different researches [15].

Compared with emerging contaminants, heavy metals might pose higher risks [16-18]. Heavy metal pollution 
and emerging contaminants have attracted attention widely [19-22]. FTC is one of the critical processes that influence heavy metal behaviors through changing soilspecific surface area, organic matter content, physical structure, and other soil properties [23-25]. Many studies have demonstrated that the geochemistry behavior of some heavy metals can be altered by FTCs [26, 27]. It is generally regarded that adsorption and desorption of heavy metals in unfrozen soils were higher than the soil with FT-treatment $[3,27]$, but this study has different results. The soil adsorption amount of heavy metals increased with the decreased freezing temperature and FTC frequency $[3,28]$. FTCs can also transport the particulate metals from soil environment to aquatic environment $[25,29]$. Moreover, FTCs are important functions for the transform of heavy metals from organic or Fe-Mn oxides fractions to exchangeable fractions [30, 31]. However, most studies adopted extreme freeze-thaw conditions; for example, the researchers usually adopted $-25^{\circ} \mathrm{C}$ as freezing temperature and $20^{\circ} \mathrm{C}$ as thawing temperature $[25,32]$. The minimum temperature in a natural environment below $-20^{\circ} \mathrm{C}$ rarely exists in soil when the FTCs occur. Therefore, the researchers should adopt a suitable temperature for the freeze-thaw conditions.

FTC is a typical climate characteristic in northwest China. Little information has been available on the adsorption and desorption of heavy metals in soils of QinghaiTibet Plateau experiencing FTCs. The immobilization processes of heavy metals in soil would be impacted by the property change caused by FTCs, which can cause variations in the soil environment. In this study, we took the soils of the northeastern Qinghai-Tibet Plateau in China as the research objects and probed into the behaviors of the adsorption and desorption of $\mathrm{Cr}$ and $\mathrm{Pb}$ in soils treated with different freezethaw conditions. The main targets of this were to (1) investigate isothermal adsorption and desorption behavior of $\mathrm{Pb}$ and $\mathrm{Cr}$ in the freeze-thaw treated (FT-treated) soils and (2) study kinetics of adsorption and desorption behavior of $\mathrm{Pb}$ and $\mathrm{Cr}$ in the FT-treated soils.

\section{Materials and Methods}

2.1. Site Description and Soil Samples. The experimental soils were sampled from top $20 \mathrm{~cm}$ layers in northeastern Qinghai-Tibet Plateau, China. The soil sampling sites included S-1 in background area $\left(35.08^{\circ} \mathrm{N} ; 97.75^{\circ} \mathrm{E}\right), \mathrm{S}-2$ in agricultural and pastoral area $\left(36.98^{\circ} \mathrm{N} ; 100.85^{\circ} \mathrm{E}\right), \mathrm{S}-3$ in industrial area $\left(36.38^{\circ} \mathrm{N} ; 94.94^{\circ} \mathrm{E}\right), \mathrm{S}-4$ in mining area $\left(37.32^{\circ} \mathrm{N} ; 95.55^{\circ} \mathrm{E}\right), \mathrm{S}-5$ in salt-lake area $\left(36.75^{\circ} \mathrm{N} ; 99.07^{\circ} \mathrm{E}\right)$, and S-6 in urban area $\left(36.63^{\circ} \mathrm{N} ; 101.75^{\circ} \mathrm{E}\right)$. Roots, stones, and vegetation were removed, and the soils were air-dried, mixed, and stored at $4^{\circ} \mathrm{C}$ in the dark until use.

The ground of the Qinghai-Tibet plateau is mainly classified into two major categories on the map of permafrost on the Qinghai-Tibetan Plateau (QTP 1996): permafrost and seasonally frozen [1]. The freezing-thawing phenomenon is distributed in this region widely. The freezing and thawing temperatures of the lab-simulated experiments were set as $-15^{\circ} \mathrm{C}$ and $+5^{\circ} \mathrm{C}$, respectively.
2.2. Freeze-Thaw Procedure. About $200 \mathrm{~g}$ of soil samples were put into plastic bags. Soil moistures were adjusted to $60 \%$ and $100 \%$ water holding capacity. The freezing temperature $\left(-15^{\circ} \mathrm{C}\right)$ and thawing temperature $\left(+5^{\circ} \mathrm{C}\right)$ were selected to simulate the common winter temperature in northwest China. In the simulated experiments, the soil samples with different water contents were frozen under $-15^{\circ} \mathrm{C}$ for $24 \mathrm{~h}$ and then thawed under $5^{\circ} \mathrm{C}$ for the next $24 \mathrm{~h}$; the above processes were set as one FTC. The freeze-thaw processes of samples were conducted by a refrigerator (BCD649WE, Qingdao Haier Co. Ltd., Qingdao, China). After 15 FTCs, samples of FT-treatment were air-dried and labeled as $\mathrm{F} 15+\mathrm{W} 60 \%$ and $\mathrm{F} 15+\mathrm{W} 100 \%$, respectively. The unfrozen soil was kept under $5^{\circ} \mathrm{C}$ and labeled as $\mathrm{F} 0+\mathrm{W} 0 \%$.

\section{3. $\mathrm{Pb}$ and $\mathrm{Cr}$ Adsorption and Desorption Experiments.} For each FT-treatment, about $1.0 \mathrm{~g}$ of treated soil sample was put into a $50 \mathrm{~mL}$ centrifuge tube. All the experiments were conducted at a fixed ionic strength $\left(\mathrm{NaNO}_{3}\right.$, analysis pure, Sinopharm Chemical Reagent Co. Ltd.). In order to illustrate the effect of water-soil ratio on adsorption of FT-treated soils, the solutions of $0.01 \mathrm{~mol} / \mathrm{L} \mathrm{NaNO}_{3}$ containing $20 \mathrm{mg} / \mathrm{L} \mathrm{Pb}^{2+}$ $\left(\mathrm{Pb}\left(\mathrm{NO}_{3}\right)_{2}\right.$, analysis pure, Sinopharm Chemical Reagent Co. Ltd.) and $10 \mathrm{mg} / \mathrm{L} \mathrm{Cr}^{6+}\left(\mathrm{K}_{2} \mathrm{Cr}_{2} \mathrm{O}_{7}\right.$, analysis pure, DaMao Chemical Reagent Factory) were added to each tube. The $\mathrm{Pb}^{2+}$ and $\mathrm{Cr}^{6+}$ solution of volumes consisted of $10,30,50$, and $80 \mathrm{~mL}$, respectively. The $\mathrm{Pb}^{2+}$ contents of solutions were $0.2,0.6,1.0$, and $1.6 \mathrm{mg}$, while the $\mathrm{Cr}^{6+}$ contents of solutions were $0.1,0.3$, 0.5 , and $0.8 \mathrm{mg}$, respectively. Then the tubes were shaken at 180 times/min continuously for $2 \mathrm{~h}$; the samples were centrifuged at $4000 \mathrm{rpm}$ for $10 \mathrm{~min}$ and filtered through a $0.45 \mu \mathrm{m}$ cellulose acetate syringe filter. The $\mathrm{Pb}$ and $\mathrm{Cr}$ concentration of the supernatants was measured by plasma emission spectrometer (Thermo ICAP 6500 DUO, Thermo Fisher, USA). The adsorption capacity of $\mathrm{Pb}$ and $\mathrm{Cr}$ were calculated as follows:

$$
S_{a}=\frac{\left(C_{0}-C_{1}\right)}{m} \times V,
$$

where $S_{a}$ is the adsorption capacity $(\mathrm{mg} / \mathrm{kg}), C_{0}$ is the initial $\mathrm{Pb}$ or $\mathrm{Cr}$ concentration in $\mathrm{mg} / \mathrm{L}, \mathrm{C}_{1}$ is the $\mathrm{Pb}$ or $\mathrm{Cr}$ concentration of equilibrium $(\mathrm{mg} / \mathrm{L}), V$ is the volume of added solution (L), and $m$ is the weight of soil sample $(\mathrm{kg})$.

For each sample, about $1.0 \mathrm{~g}$ of air-dried soil sample was placed in a $50 \mathrm{~mL}$ centrifuge tube. A $20 \mathrm{~mL}$ solution of $0.01 \mathrm{~mol} / \mathrm{L} \mathrm{NaNO}_{3}$ containing varying concentrations of $\mathrm{Pb}$ and $\mathrm{Cr}$ was added to each tube. Solutions containing various concentrations $(5,10,20,50$, and $100 \mathrm{mg} / \mathrm{L})$ of $20 \mathrm{~mL} \mathrm{~Pb}^{2+}$ $\left(\mathrm{Pb}\left(\mathrm{NO}_{3}\right)_{2}\right.$ solution) and various concentrations $(5,10,20$, 30 , and $50 \mathrm{mg} / \mathrm{L})$ of $20 \mathrm{~mL} \mathrm{Cr}{ }^{6+}\left(\mathrm{K}_{2} \mathrm{Cr}_{2} \mathrm{O}_{7}\right.$ solution) were prepared. These experiments aimed to assess isothermal adsorption of FT-treated soils. Then the tubes were shaken at 180 times/min continuously for $2 \mathrm{~h}$ and then centrifuged at $4000 \mathrm{rpm}$ for $10 \mathrm{~min}$. The supernatants were filtered through a $0.45 \mu \mathrm{m}$ cellulose acetate syringe filter.

Following the adsorption experiments of $\mathrm{Pb}$ or $\mathrm{Cr}$, the centrifuged residues were weighed to calculate the content of residual solutions. Then $20 \mathrm{~mL}$ of $0.01 \mathrm{~mol} / \mathrm{L} \mathrm{NaNO}_{3}$ solutions were added to the centrifuged residues. The tubes were shaken 
for $2 \mathrm{~h}$. The concentrations of $\mathrm{Pb}$ or $\mathrm{Cr}$ in the supernatant were measured as described above. The amount of desorbed $\mathrm{Pb}$ or $\mathrm{Cr}$ was calculated according to the following equation:

$$
S_{d}=\frac{C_{2} \times V-C_{1} \times V_{1}}{m},
$$

where $S_{d}$ is the desorption capacity in $\mathrm{mg} / \mathrm{kg}, C_{2}$ is the $\mathrm{Pb}$ or $\mathrm{Cr}$ concentration of equilibrium $(\mathrm{mg} / \mathrm{L})$, and $V_{1}$ is the volume remaining in the residue.

The isothermal adsorption behavior of $\mathrm{Pb}$ and $\mathrm{Cr}$ in the soil is calculated by the Freundlich and Langmuir models. The Freundlich model explains site adsorption intensity and heterogeneity between adsorbate and adsorbent [33]. The Freundlich equation has the following form:

$$
\log Q_{e}=\log k+\frac{1}{n} \log C_{e},
$$

where $Q_{e}$ is $\mathrm{Pb}$ or $\mathrm{Cr}$ adsorbed by soil $(\mathrm{mg} / \mathrm{kg}), C_{e}$ is $\mathrm{Pb}$ or $\mathrm{Cr}$ concentration in adsorption equilibrium $(\mathrm{mg} / \mathrm{L}), n$ is constant, and $k$ is affinity coefficient $(\mathrm{L} / \mathrm{mg})$.

Langmuir model assumes that maximum adsorption corresponds to a saturated monolayer of solute molecules on the surface of the adsorbent [33], and the energy of adsorbance is constant. The Langmuir model is calculated according to the following equation:

$$
\frac{C_{e}}{Q_{e}}=\frac{1}{Q_{m}} \times C_{e}+\frac{1}{k \times Q_{m}},
$$

where $Q_{e}$ is $\mathrm{Pb}$ or Cr adsorbed by soil (mg/kg), $C_{e}$ is $\mathrm{Pb}$ or $\mathrm{Cr}$ concentration in adsorption equilibrium $(\mathrm{mg} / \mathrm{L}), Q_{m}$ is the adsorption maximum of $\mathrm{Pb}$ or $\mathrm{Cr}$ adsorbed by soil, and $k$ is affinity coefficient $(\mathrm{L} / \mathrm{mg})$.

In order to illustrate the soil kinetics of adsorption, about $1.0 \mathrm{~g}$ of treated soil samples were put into a $50 \mathrm{~mL}$ solution centrifuge tube. The solutions of $0.01 \mathrm{~mol} / \mathrm{L} \mathrm{NaNO}_{3}$ containing $20 \mathrm{mg} / \mathrm{L} \mathrm{Pb}^{2+}\left(\mathrm{Pb}\left(\mathrm{NO}_{3}\right)_{2}\right.$ solution $)$ and $10 \mathrm{mg} / \mathrm{L} \mathrm{Cr}^{6+}$ $\left(\mathrm{K}_{2} \mathrm{Cr}_{2} \mathrm{O}_{7}\right.$ solution) were added to each tube. Supernatants were collected from the tubes at 5, 10, 30, 60, 240, and 480 minutes. The following experiment processes were the same as described above, and the concentrations of $\mathrm{Pb}^{2+}$ or $\mathrm{Cr}^{6+}$ in the supernatant were measured as described above.

The pseudo-first-order model is a conventional model examined to analyse the kinetics of adsorption processes. The pseudo-first-order kinetics model supposes that the diffusion step controls the adsorption and its adsorption is proportional to the difference in adsorption capacity at equilibrium and at any time [34]. The Weber-Morris model described intraparticle diffusion in the solid phase [34]. The pseudo-first-order (5) and Weber-Morris (6) models are described as follows:

$$
\begin{gathered}
\log \left(Q_{e}-Q_{t}\right)=\log Q_{e}-k_{1} t \\
Q_{t}=k_{2} t^{1 / 2}+C
\end{gathered}
$$

where $t$ is reaction time $(\mathrm{h}), Q_{e}$ and $Q_{t}$ are adsorption capacity at equilibrium and at any time $t(\mathrm{mg} / \mathrm{kg})$, and $k_{1}$ and $k_{2}$ denote pseudo-first-order rate constant and intraparticle diffusion equation constant, respectively. $C$ is a constant.

\section{Results and Discussion}

3.1. Effect of Water-Soil Ratio on Adsorption of FT-Treated Soils. The soil type in the sampling sites was sandy clay loam, and soil $\mathrm{pH}$ was an alkaline. The $\mathrm{Pb}$ and $\mathrm{Cr}$ concentrations of the selected soils would not affect the adsorption and desorption experiment because exchangeable $\mathrm{Pb}$ and $\mathrm{Cr}$ contents were under very low level. The soil performance of $\mathrm{Pb}$ and $\mathrm{Cr}$ adsorption at various water-soil ratios under different FT-treated are shown in Figure 1. The different soil adsorption trends of $\mathrm{Pb}$ and $\mathrm{Cr}$ responded more or less constantly with change in the water-soil ratios. The $\mathrm{Pb}$ and $\mathrm{Cr}$ adsorption amount mostly decreased with increasing the water-soil ratio. However, the soil performance of $\mathrm{Pb}$ and $\mathrm{Cr}$ adsorption at same water-soil ratios showed variation under different freeze-thaw conditions.

The FTCs with different freezing conditions exerted different effects on soils of the northeastern Qinghai-Tibet Plateau. At water-soil ratios of 10:1, 30:1, and 80:1, the Pb adsorption amount of soils in S-1 under different FT-treated $(\mathrm{F} 15+\mathrm{W} 60 \%$ and $\mathrm{F} 15+\mathrm{W} 100 \%)$ decreased compared to the unfrozen soil. At water-soil ratio of $50: 1$, the $\mathrm{Pb}$ adsorption amount in S-1 increased at 15 FTCs and $60 \%$ water content and decreased at 15 FTCs and $100 \%$ water content compared to the unfrozen soil. At water-soil ratio of $10: 1$, the $\mathrm{Pb}$ adsorption amount of FT-treated soils at 15 FTCs and $100 \%$ water content in S-2 was maximum value compared to the unfrozen and FT-treated soils (F15 + W60\%), and the $\mathrm{Pb}$ adsorption amount of FT-treated soils at 15 FTCs and $60 \%$ water content in S-2 was maximum value $(125.07 \mathrm{mg} / \mathrm{kg}$ and $9.9 \mathrm{mg} / \mathrm{kg}$ ) at water-soil ratios of $30: 1$ and $80: 1$. The $\mathrm{Pb}$ adsorption amount of soils in S-2 under different FT-treated $(\mathrm{F} 15+\mathrm{W} 60 \%$ and $\mathrm{F} 15+\mathrm{W} 100 \%)$ decreased compared to the unfrozen soil at a water-soil ratio of 50:1. At a water-soil ratio of 10:1, the Pb adsorption amount of unfrozen soil in S-6 was maximum value $(173.9 \mathrm{mg} / \mathrm{kg})$, the $\mathrm{Pb}$ adsorption amount of soils under different FT-treated (F15 + W60\% and F15 + W100\%) decreased compared to the frozen soil. In the soils of $\mathrm{S}-3$, the $\mathrm{Pb}$ adsorption amount of soils under different FT-treatments (F15 + W60\% and F15 + W100\%) decreased compared to the unfrozen soil at all the water-soil ratios; conversely, the soils in S-5 increased under different FT-treatments (F15 + W60\% and F15 + W100\%) at all the water-soil ratios. At different water-soil ratios, the $\mathrm{Pb}$ adsorption amount of FT-treated soils at 15 FTCs and $60 \%$ water content in S-4 was the maximum value compared to the unfrozen and FT-treated soils (F15+W100\%). At a water-soil ratio of 50:1 of soil in S-6, the changing trend was the same as a water-soil ratio of 10:1. At water-soil ratios of 30:1 and 80:1, the $\mathrm{Pb}$ adsorption amount in S-6 approached maximum values $(159.36 \mathrm{mg} / \mathrm{kg}$ and $12.5 \mathrm{mg} / \mathrm{kg})$ at $15 \mathrm{FTCs}$ and $60 \%$ water content compared to the unfrozen soil; conversely, the $\mathrm{Pb}$ adsorption amount of FT-treated soil $(\mathrm{F} 15+\mathrm{W} 100 \%)$ in S-6 decreased compared to the unfrozen soil. Base on the experimental results, the soil performance of $\mathrm{Pb}$ adsorption at the same water-soil ratios showed variation under different freeze-thaw conditions.

The Cr adsorption patterns at the same water-soil ratios were different under different FT-treatments. At water-soil ratios of 10:1 and 50:1 of soil in S-1, the Cr adsorption 


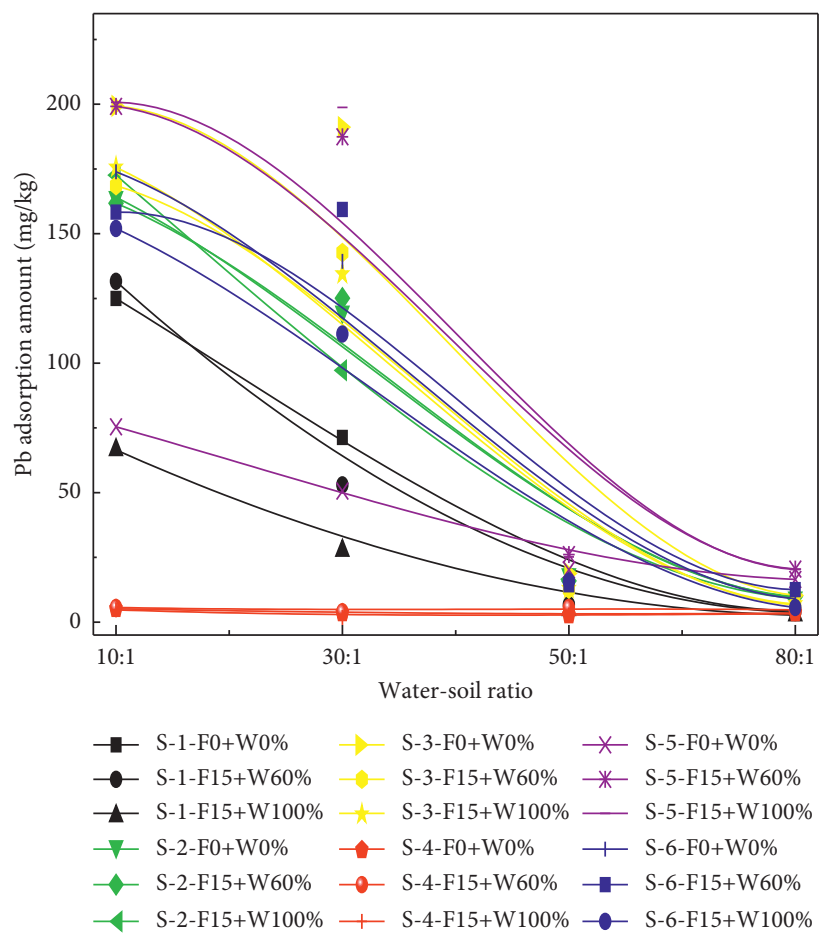

(a)

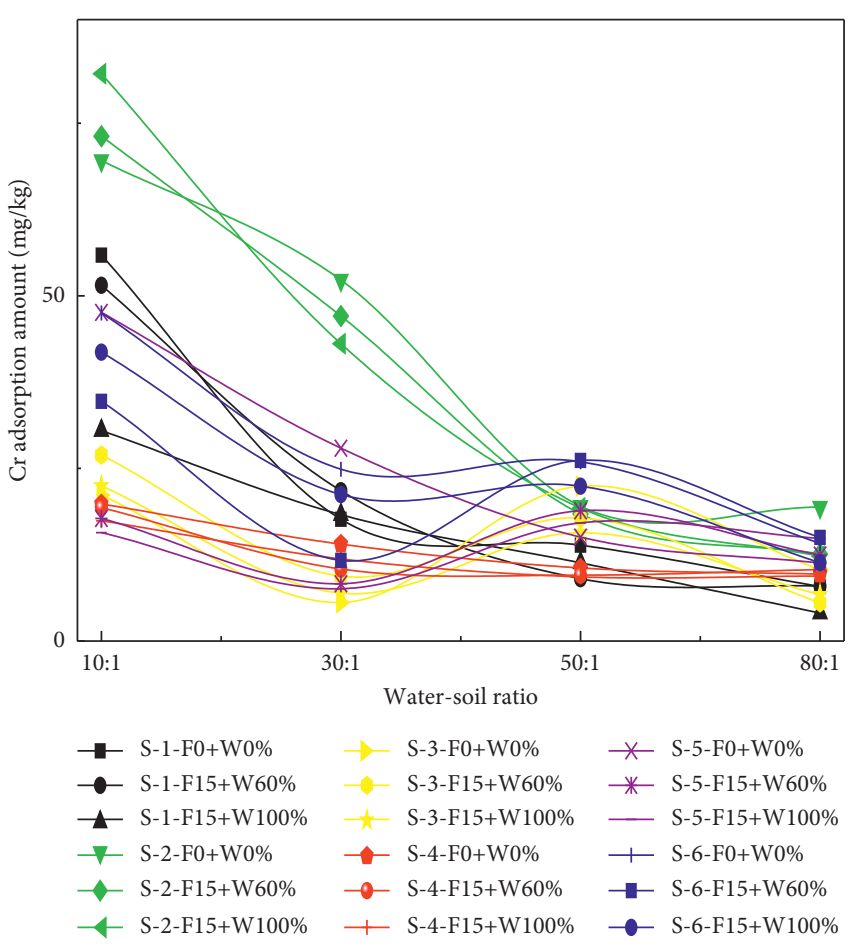

(b)

FIgURE 1: Relationship between water-soil ratio and $\mathrm{Pb}$ or $\mathrm{Cr}$ adsorption amount in soils under different freeze-thaw conditions. F0 and F15 refer to the number of freeze-thaw cycles ( 0 and 15 cycles), and W0\%, W60\%, and W $100 \%$ refer to water ratio of field capacity ( $0 \%, 60 \%$, and $100 \%$ water ratio).

amount of FT-treated soil in S-1 decreased compared to the unfrozen soil; conversely, the $\mathrm{Cr}$ adsorption amount of FTtreated soil increased at a water-soil ratio of 30:1. At a watersoil ratio of 80:1 in S-1, the Cr adsorption amount slightly increased at 15 FTCs and $60 \%$ water content and decreased at 15 FTCs and $100 \%$ water content compared to the unfrozen soil. At a water-soil ratio of 10:1 in S-2, the Cr adsorption amount of FT-treated soil increased compared to the unfrozen soil and decreased at water-soil ratios of 30:1, 50:1, and 80:1. At water-soil ratios of 10:1 and 30:1 in S-3, the $\mathrm{Cr}$ adsorption amount of FT-treated soil increased compared to the unfrozen soil and decreased at water-soil ratios of 50:1 and 80:1. At water-soil ratios of 10:1, 30:1, and 50:1 of soil in S-4, the $\mathrm{Cr}$ adsorption amount of FT-treated soil increased compared to the unfrozen soil. At water-soil ratio of 80:1 in S-4, the Cr adsorption amount slightly increased at 15 FTCs and $60 \%$ water content and slightly decreased at 15 FTCs and $100 \%$ water content compared to the unfrozen soil. At water-soil ratios of 10:1 and 30:1, the Cr adsorption amount of FT-treated soil decreased in S-5 compared to the unfrozen soil and increased at water-soil ratios of 50:1 and 80:1. At water-soil ratios of 10:1 and 30:1 of soil in S-6, the $\mathrm{Cr}$ adsorption amount of FT-treated soils in S-6 decreased compared to the unfrozen soil. At water-soil ratios of 50:1 and 80:1 in S-6, the Cr adsorption amount slightly increased at 15 FTCs and $60 \%$ water content and decreased at 15 FTCs and $100 \%$ water content compared to the unfrozen soil. The results indicated that $\mathrm{Cr}$ adsorption amount at same watersoil ratios was different under different FT-treatments.
3.2. Isothermal Adsorption and Desorption of FT-Treated Soils. $\mathrm{Pb}$ needs strict control since it can enrich in different matrices [17]. The adsorption and desorption of $\mathrm{Pb}$ in soils with different FT-treatments were shown in Figures 2(a), 2(b), 2(e), and 2(f)). A greater increase in adsorption was seen with increasing $\mathrm{Pb}$ concentrations from 0 to $20 \mathrm{mg} / \mathrm{kg}$ for the FT-treatments in the soils of S-1 and S-2, compared to adsorption with $\mathrm{Pb}$ concentrations ranging from 20 to $100 \mathrm{mg} / \mathrm{kg}$. A greater increase in adsorption was seen with increasing $\mathrm{Pb}$ concentrations from 0 to $100 \mathrm{mg} / \mathrm{kg}$ for the most FT-treatments in the soils of S-3, S-5, and S-6. A greater increase in adsorption was seen with increasing $\mathrm{Pb}$ concentrations from 0 to $100 \mathrm{mg} / \mathrm{kg}$ for the treatment of 15 FTCs and 60\% water content in S-4. A slight increase in adsorption was seen with increasing $\mathrm{Pb}$ concentrations from 0 to $50 \mathrm{mg} / \mathrm{kg}$, and a greater increase ranging from 50 to $100 \mathrm{mg} / \mathrm{kg}$ for the treatment of 15 FTCs and $60 \%$ water content in S-4. The soil adsorption amount increased by the $\mathrm{Pb}$ concentration ranging from 0 to $50 \mathrm{mg} / \mathrm{kg}$ and decreased by the $\mathrm{Pb}$ concentration ranging from 50 to $100 \mathrm{mg} / \mathrm{kg}$ for the treatment of 15 FTCs and 100\% water content in S-4. A high slope at $\mathrm{Pb}$ concentration illustrated a high proportion of available adsorption sites distribute on the surface of soil particles. In general, the adsorption of $\mathrm{Pb}$ was higher for most FT-treatments compared to the control. The desorption levels of $\mathrm{Pb}$ in soils by $0.01 \mathrm{~mol} / \mathrm{L} \mathrm{NaNO}_{3}$ with different FT-treatments were shown in Figures 2(e) and 2(f)). About $0.08-10.52 \%$ (average value: $3.18 \%$ ) of adsorbed $\mathrm{Pb}$ was desorbed from the soil without FTCs, while $0.02-10.67 \%$ 


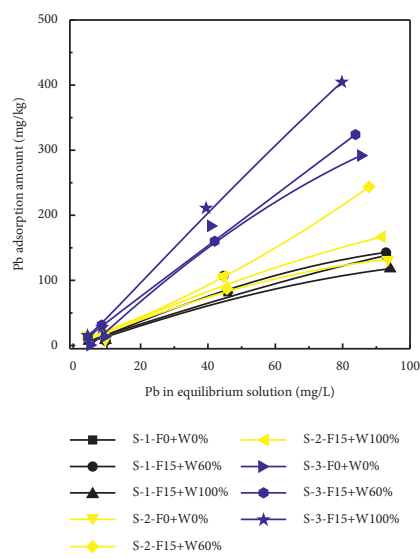

(a)

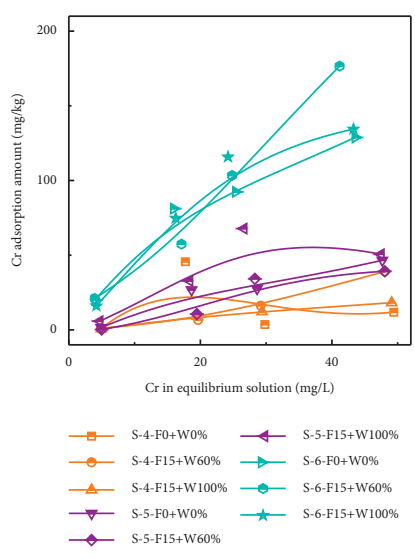

(d)

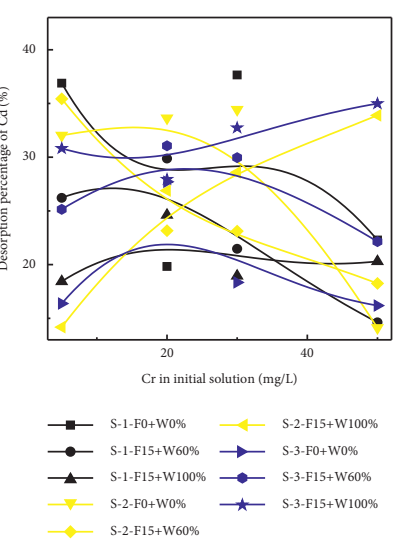

(g)

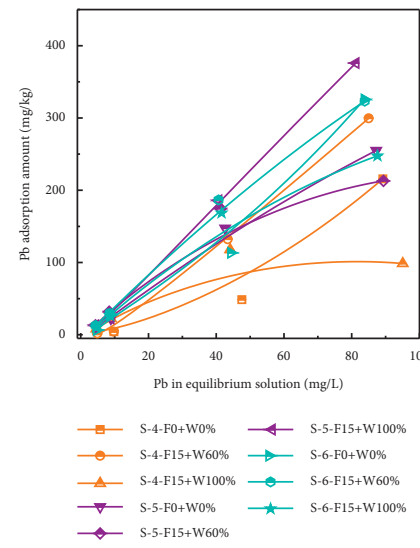

(b)

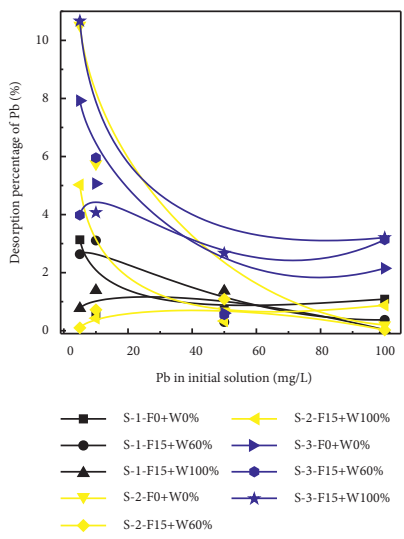

(e)

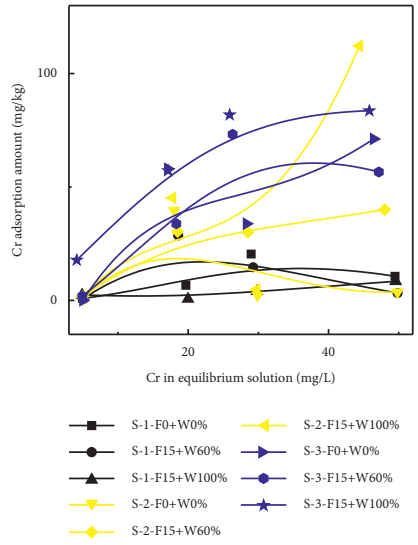

(c)
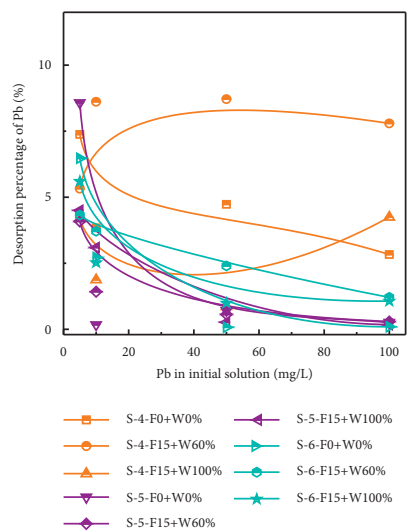

(f)

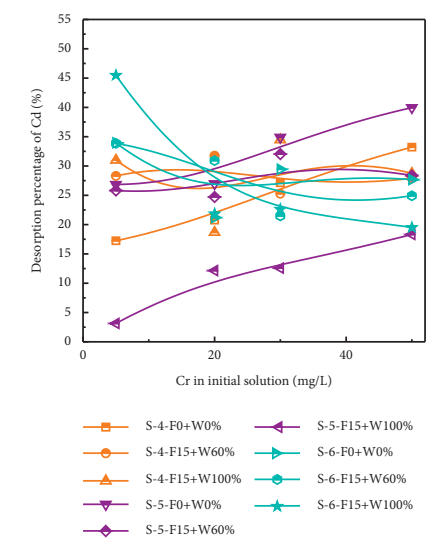

(h)

Figure 2: Adsorption amounts and desorption rates for $\mathrm{Pb}$ and $\mathrm{Cr}$ by soils under different freeze-thaw conditions. F0 and F15 refer to the number of freeze-thaw cycles ( 0 and 15 cycles), and W0\%, W60\%, and $\mathrm{W} 100 \%$ refer to water ratio of field capacity $(0 \%, 60 \%$, and $100 \%$ water ratio).

(average value: $2.91 \%$ ) of adsorbed $\mathrm{Pb}$ was desorbed from FT-treated soils at the same initial concentration of $\mathrm{Pb}$. These data indicated that electrostatic binding of $\mathrm{Pb}$ in most soil samples was stronger under FTCs.

The $\mathrm{Pb}$ Langmuir and Freundlich parameters and data values are shown in Table 1 . The $1 / n$ in the Freundlich model is a measure of the heterogeneity of adsorption sites on the adsorbent surface. Surface site heterogeneity increases with
$1 / n$ approaches 0 . Conversely, surface site homogeneity increases with $1 / n$ approaches unity [35]. For the control with unfrozen soil, the $1 / n$ value was higher at $0.87 \pm 0.01$ in soils of S-1, while the $1 / n$ values for the FT-treatments $(\mathrm{F} 15+\mathrm{W} 60 \%$ and $\mathrm{F} 15+\mathrm{W} 100 \%)$ were lower at $0.78 \pm 0.24$ and $0.78 \pm 0.21$, respectively. This indicated that surface site homogeneity decreases with FT-treatment. The soils in S-4 and S- 6 were similar to the soils of S-1 under the same FT- 
TABLE 1: Freundlich and Langmuir parameters of $\mathrm{Pb}$ in soils under different freeze-thaw conditions.

\begin{tabular}{|c|c|c|c|c|c|c|c|}
\hline \multirow{2}{*}{ Site area } & \multirow{2}{*}{ FTCs } & \multicolumn{3}{|c|}{$\mathrm{Pb}$ (Freundlich) } & \multicolumn{3}{|c|}{$\mathrm{Pb}$ (Langmuir) } \\
\hline & & $1 / n$ & $k$ & $r^{2}$ & $Q_{m}(\mathrm{mg} / \mathrm{kg})$ & $k$ & $r^{2}$ \\
\hline \multirow{3}{*}{ S-1 } & $\mathrm{F} 0+\mathrm{W} 0 \%$ & $0.87 \pm 0.10$ & $2.69 \pm 1.20$ & 0.99 & $530.65 \pm 244.75$ & $0.003 \pm 0.002$ & 0.99 \\
\hline & $\mathrm{F} 15+\mathrm{W} 60 \%$ & $0.78 \pm 0.24$ & $4.40 \pm 4.72$ & 0.93 & $319.98 \pm 201.15$ & $0.009 \pm 0.009$ & 0.95 \\
\hline & $\mathrm{F} 15+\mathrm{W} 100 \%$ & $0.78 \pm 0.21$ & $3.51 \pm 3.25$ & 0.95 & $269.37 \pm 144.31$ & $0.008 \pm 0.007$ & 0.97 \\
\hline \multirow{3}{*}{$S-2$} & $\mathrm{~F} 0+\mathrm{W} 0 \%$ & $0.69 \pm 0.23$ & $6.08 \pm 6.08$ & 0.91 & $244.18 \pm 116.17$ & $0.01 \pm 0.01$ & 0.95 \\
\hline & $\mathrm{F} 15+\mathrm{W} 60 \%$ & $1.47 \pm 0.18$ & $0.32 \pm 0.26$ & 0.99 & - & - & - \\
\hline & $\mathrm{F} 15+\mathrm{W} 100 \%$ & $0.83 \pm 0.13$ & $3.96 \pm 2.38$ & 0.98 & $484.57 \pm 211.89$ & $0.005 \pm 0.003$ & 0.99 \\
\hline \multirow{3}{*}{$S-3$} & $\mathrm{~F} 0+\mathrm{W} 0 \%$ & $0.92 \pm 0.22$ & $4.92 \pm 4.87$ & 0.96 & $1181.38 \pm 1453.03$ & $0.003 \pm 0.006$ & 0.97 \\
\hline & $\mathrm{F} 15+\mathrm{W} 60 \%$ & $1.02 \pm 0.01$ & $3.41 \pm 0.28$ & 0.99 & - & - & - \\
\hline & $\mathrm{F} 15+\mathrm{W} 100 \%$ & $1.02 \pm 0.08$ & $4.68 \pm 1.67$ & 0.99 & $20390.80 \pm 142821.15$ & $2.54 E-4 \pm 0.001$ & 0.99 \\
\hline \multirow{3}{*}{ S-4 } & $\mathrm{F} 0+\mathrm{W} 0 \%$ & $2.35 \pm 0.13$ & $0.005 \pm 0.003$ & 0.99 & - & - & - \\
\hline & $\mathrm{F} 15+\mathrm{W} 60 \%$ & $1.31 \pm 0.12$ & $0.88 \pm 0.498$ & 0.99 & - & - & - \\
\hline & $\mathrm{F} 15+\mathrm{W} 100 \%$ & $0.50 \pm 0.30$ & $11.69 \pm 14.77$ & 0.74 & - & - & - \\
\hline \multirow{3}{*}{$S-5$} & $\mathrm{~F} 0+\mathrm{W} 0 \%$ & $0.90 \pm 0.10$ & $4.55 \pm 2.0$ & 0.99 & $1158.05 \pm 632.67$ & $0.003 \pm 0.002$ & 0.99 \\
\hline & $\mathrm{F} 15+\mathrm{W} 60 \%$ & $0.64 \pm 0.20$ & $12.37 \pm 10.54$ & 0.92 & $353.76 \pm 105.46$ & $0.01 \pm 0.01$ & 0.96 \\
\hline & $\mathrm{F} 15+\mathrm{W} 100 \%$ & $1.08 \pm 0.06$ & $3.14 \pm 0.94$ & 0.99 & - & - & - \\
\hline \multirow{3}{*}{ S-6 } & F0 + W0\% & $1.57 \pm 0.18$ & $0.29 \pm 0.24$ & 0.99 & - & - & - \\
\hline & $\mathrm{F} 15+\mathrm{W} 60 \%$ & $0.89 \pm 0.10$ & $6.12 \pm 2.67$ & 0.99 & $1413.49 \pm 734.43$ & $0.003 \pm 0.002$ & 0.99 \\
\hline & $\mathrm{F} 15+\mathrm{W} 100 \%$ & $0.78 \pm 0.16$ & $7.81 \pm 5.504$ & 0.96 & $309.57 \pm 1.53$ & $0.002 \pm 9.06 E-5$ & 1.00 \\
\hline
\end{tabular}

Note. "-" means that these data could not be fitted using the Freundlich and Langmuir models. F0 and F15 refer to the number of freeze-thaw cycles $(0$ and 15 cycles), and $\mathrm{W} 0 \%, \mathrm{~W} 60 \%$, and $\mathrm{W} 100 \%$ refer to water ratio of field capacity (0\%, $60 \%$, and $100 \%$ water ratio).

treatments; conversely, the $1 / n$ values in soils of S-2 and S-3 under FT-treatments increased compared to the control with no FT-treatment. The results indicated that surface site homogeneity increased with FT-treatments in soils of S-2 and S-3. Compared to the control with no FT-treatment, the $1 / n$ value was higher at $0.87 \pm 0.01$ under 15 FTCs and $100 \%$ water content in soil of S-5, while the $1 / n$ values for the FTtreatment $(\mathrm{F} 15+\mathrm{W} 60 \%)$ were lower at $0.64 \pm 0.20$. The results indicate that different adsorption patterns were observed in different FT-treatments and different sampling sites.

The $Q_{m}$ value in the Langmuir model represented the maximum adsorption capacity of $\mathrm{Pb}$ to the soil. According to Table 1, parts of data could not be fitted using the Langmuir model. Only the soils in S-1 under unfrozen and different freeze-thaw conditions could be all fitted the Langmuir model. The $Q_{m}$ values indicated that maximum adsorption of $\mathrm{Pb}$ to the soil of S-1 decreased with FT-treatments. Maximum adsorption for the control was $530.65 \pm 244.75 \mathrm{mg} / \mathrm{kg}$, while $Q_{m}$ values were $\quad 319.98 \pm 201.15 \mathrm{mg} / \mathrm{kg}$ for FT-treatment $(\mathrm{F} 15+\mathrm{W} 60 \%)$ and $269.37 \pm 144.31 \mathrm{mg} / \mathrm{kg}$ for FT-treatment $(\mathrm{F} 15+\mathrm{W} 100 \%)$. The $K$ term in the Langmuir model equation indicates adsorption energy. As $K$ values increase, the binding energy between soil colloids and ions increases. The results showed that $K$ values of soils in S-1 increased under FT-treatments. The results suggested that the binding energy between soil colloid and $\mathrm{Pb}$ increased under FT-treatments.

The adsorption and desorption of $\mathrm{Cr}$ in soils with different FT-treatments are shown in Figures 2(c), 2(d), 2(g), and $2(\mathrm{~h})$ ). A slight change in adsorption was shown with increasing Cr concentration from 0 to $50 \mathrm{mg} / \mathrm{kg}$ for the most
FT-treatments in the soils of S-1, S-4, and S-5. A greater increase in adsorption was seen with increasing $\mathrm{Cr}$ concentrations from 0 to $20 \mathrm{mg} / \mathrm{kg}$ for the most FT-treatments in the soils of S-2 and S-3, compared to adsorption with $\mathrm{Cr}$ concentrations ranging from 20 to $50 \mathrm{mg} / \mathrm{kg}$. A greater increase in adsorption was seen with increasing $\mathrm{Cr}$ concentrations from 0 to $50 \mathrm{mg} / \mathrm{kg}$ for the most FT-treatments in the soils of S-6. In general, the adsorption of $\mathrm{Cr}$ had no regular pattern among these soil samples under different FTtreatments and unfrozen conditions. Desorption amount of $\mathrm{Cr}$ in soils by $0.01 \mathrm{~mol} / \mathrm{L} \mathrm{NaNO}_{3}$ with different FT-treatments are shown in Figures $2(\mathrm{~g})$ and $2(\mathrm{~h}))$. About $14.11-39.95 \%$ (average value: $27.03 \%$ ) of adsorbed $\mathrm{Pb}$ was desorbed from the soil without FT-treatment, while $3.13-45.47 \%$ (average value: $25.34 \%$ ) of adsorbed $\mathrm{Cr}$ was desorbed from FT-treated soils at the same initial concentration of Cr. These results indicated that the electrostatic binding of $\mathrm{Cr}$ in most soil samples was stronger under freeze-thaw conditions.

The Cr Langmuir and Freundlich parameters in different soils under different freeze-thaw conditions are shown in Table 2. Compared to the control with no FTtreatment, the $1 / n$ value was higher at $1.75 \pm 0.81$ under 15 FTCs and $100 \%$ water content in soil of S-1, while the $1 / n$ values for the FT-treatment $(\mathrm{F} 15+\mathrm{W} 60 \%)$ were lower at $0.13 \pm 0.82$. For the control with unfrozen soil, the $1 / n$ value was higher at $0.71 \pm 0.51$ in soils of $S-3$, while the $1 / n$ values for the FT-treatments $(\mathrm{F} 15+\mathrm{W} 60 \%$ and $\mathrm{F} 15+\mathrm{W} 100 \%)$ were lower at $0.62 \pm 0.47$ and $0.50 \pm 0.17$, respectively. These results indicated that surface site homogeneity decreased with FT-treatment. Conversely, the $1 / n$ values in soils of S-2, S- 4 , and S- 6 under FTtreatments increased compared to the control with no 
TABLE 2: Freundlich and Langmuir parameters of $\mathrm{Cr}$ in soils under different freeze-thaw conditions.

\begin{tabular}{|c|c|c|c|c|c|c|c|}
\hline \multirow{2}{*}{ Site area } & \multirow{2}{*}{ FTCs } & \multicolumn{3}{|c|}{ Cr (Freundlich) } & \multicolumn{3}{|c|}{ Cr (Langmuir) } \\
\hline & & $1 / n$ & $k$ & $r^{2}$ & $Q_{m}(\mathrm{mg} / \mathrm{kg})$ & $k$ & $r^{2}$ \\
\hline \multirow{3}{*}{ S-1 } & $\mathrm{F} 0+\mathrm{W} 0 \%$ & $0.54 \pm 0.68$ & $1.80 \pm 4.39$ & 0.40 & - & - & - \\
\hline & $\mathrm{F} 15+\mathrm{W} 60 \%$ & $0.13 \pm 0.82$ & $7.97 \pm 21.32$ & 0.02 & - & - & - \\
\hline & $\mathrm{F} 15+\mathrm{W} 100 \%$ & $1.75 \pm 0.81$ & $0.01 \pm 0.02$ & 0.80 & - & - & - \\
\hline \multirow{3}{*}{$S-2$} & $\mathrm{~F} 0+\mathrm{W} 0 \%$ & $0.34 \pm 0.53$ & $9.95 \pm 18.12$ & 0.27 & - & - & - \\
\hline & $\mathrm{F} 15+\mathrm{W} 60 \%$ & $0.65 \pm 0.28$ & $3.30 \pm 3.37$ & 0.84 & $70.98 \pm 40.99$ & $0.02 \pm 0.03$ & 0.89 \\
\hline & $\mathrm{F} 15+\mathrm{W} 100 \%$ & - & - & - & - & - & - \\
\hline \multirow{3}{*}{$S-3$} & $\mathrm{~F} 0+\mathrm{W} 0 \%$ & $0.71 \pm 0.51$ & $4.53 \pm 8.33$ & 0.65 & - & - & - \\
\hline & $\mathrm{F} 15+\mathrm{W} 60 \%$ & $0.62 \pm 0.47$ & $6.18 \pm 10.43$ & 0.63 & - & - & - \\
\hline & $\mathrm{F} 15+\mathrm{W} 100 \%$ & $0.50 \pm 0.17$ & $13.17 \pm 7.78$ & 0.88 & $124.76 \pm 27.89$ & $0.05 \pm 0.02$ & 0.95 \\
\hline \multirow{3}{*}{ S-4 } & $\mathrm{F} 0+\mathrm{W} 0 \%$ & $0.11 \pm 1.00$ & $10.92 \pm 35.26$ & 0.01 & - & - & - \\
\hline & $\mathrm{F} 15+\mathrm{W} 60 \%$ & $1.85 \pm 0.08$ & $0.02 \pm 0.01$ & 0.99 & - & - & - \\
\hline & $\mathrm{F} 15+\mathrm{W} 100 \%$ & $0.883 \pm 0.14$ & $0.59 \pm 0.32$ & 0.97 & $76.20 \pm 59.68$ & $0.01 \pm 0.01$ & 0.98 \\
\hline \multirow{3}{*}{ S-5 } & $\mathrm{F} 0+\mathrm{W} 0 \%$ & $0.86 \pm 0.23$ & $1.67 \pm 1.45$ & 0.93 & $172.81 \pm 218.09$ & $0.01 \pm 0.01$ & 0.93 \\
\hline & $\mathrm{F} 15+\mathrm{W} 60 \%$ & $1.02 \pm 0.46$ & $0.78 \pm 1.36$ & 0.85 & $482.39 \pm 3870.92$ & $0.001 \pm 0.01$ & 0.85 \\
\hline & $\mathrm{F} 15+\mathrm{W} 100 \%$ & $0.54 \pm 0.42$ & $7.41 \pm 10.98$ & 0.62 & - & - & - \\
\hline \multirow{3}{*}{ S-6 } & $\mathrm{F} 0+\mathrm{W} 0 \%$ & $0.62 \pm 0.11$ & $12.62 \pm 4.99$ & 0.96 & $219.48 \pm 43.91$ & $0.03 \pm 0.01$ & 0.98 \\
\hline & $\mathrm{F} 15+\mathrm{W} 60 \%$ & $1.13 \pm 0.12$ & $2.60 \pm 1.152$ & 0.98 & - & - & - \\
\hline & $\mathrm{F} 15+\mathrm{W} 100 \%$ & $0.66 \pm 0.18$ & $11.73 \pm 7.52$ & 0.92 & $260.33 \pm 93.79$ & $0.02 \pm 0.01$ & 0.95 \\
\hline
\end{tabular}

Note. "-" means that these data could not be fitted using the Freundlich and Langmuir models. F0 and F15 refer to the number of freeze-thaw cycles $(0$ and 15 cycles), and $\mathrm{W} 0 \%, \mathrm{~W} 60 \%$, and $\mathrm{W} 100 \%$ refer to water ratio of field capacity $(0 \%, 60 \%$, and $100 \%$ water ratio).

FT-treatment. These results indicated that surface site homogeneity increased with FT-treatments in soils of S-2, S-4, and S-6. Compared to the control with no FTtreatment, the $1 / n$ value was higher at $1.02 \pm 0.46$ under 15 FTCs and $60 \%$ water content in soil of S-5, while the $1 /$ $n$ value for the FT-treatment (F15 + W100\%) was lower at $0.54 \pm 0.42$. According to Table 2, most data of $\mathrm{Cr}$ adsorption could not be fitted using the Langmuir model. The results indicated that different adsorption patterns were observed in different FT-treatments and different sampling areas.

3.3. Adsorption Kinetics of FT-Treated Soils. In order to optimize the time required for access to equilibrium condition, a series of adsorption experiments were performed. This investigation also allowed verifying the kinetics of the process. The adsorption of $\mathrm{Pb}$ and $\mathrm{Cr}$ from aqueous solution to about $1 \mathrm{~g}$ of soil was studied by contacting the solid and liquid phases in the range of 5-480 minutes (Figure 3).

Base on pseudo-first-order model analysis, the equilibrium of adsorption of $\mathrm{Pb}$ ions was not achieved after 480 minutes for soil under unfrozen in S-1, 458 minutes for soil under 15 FTCs and $60 \%$ water content, and 376 minutes for soil under 15 FTCs and $100 \%$ water content. Equilibrium of adsorption of $\mathrm{Pb}$ ions was achieved after $3.33 \mathrm{~h}$ for soil under unfrozen in S-3, $0.72 \mathrm{~h}$ for soil under $15 \mathrm{FTCs}$ and $60 \%$ water content, and $0.90 \mathrm{~h}$ for soil under 15 FTCs and $100 \%$ water content. Equilibrium of adsorption of $\mathrm{Pb}$ ions was not achieved after $480 \mathrm{~min}$ for soil under unfrozen in S-5, $0.70 \mathrm{~h}$ for soil under 15 FTCs and $60 \%$ water content, and $0.74 \mathrm{~h}$ for soil under 15 FTCs and $100 \%$ water content. These results demonstrated that the kinetics of $\mathrm{Pb}$ adsorption under FTtreatments were more rapid than the unfrozen soil in the S-1,
$\mathrm{S}-3$, and S-5. Equilibrium of adsorption of $\mathrm{Pb}$ ions was achieved after $7.84 \mathrm{~h}$ for soil under unfrozen and FTtreatment $(\mathrm{F} 15+\mathrm{W} 100 \%)$ in S-2; it was seen that the adsorption of $\mathrm{Pb}$ ions onto soil under 15 FTCs and $60 \%$ water content was more rapid than unfrozen and other FTtreatment. The adsorption of $\mathrm{Pb}$ ions onto soil in S-6 under 15 FTCs and $60 \%$ water content was more rapid than unfrozen and other FT-treatment. The results indicated that most $\mathrm{Pb}$ adsorption patterns on soils under FT-conditions were rapid than unfrozen conditions.

Table 3 lists the kinetic parameters for the models on the adsorption of $\mathrm{Pb}$ onto soils in six sites. $R^{2}$ for the $\mathrm{Pb}$ pseudofirst-order model ranged from 0.46 to 0.94 . Most of the $R^{2}$ data were larger than 0.6 , except soil in S-2 under unfrozen condition, soil in S-3 under FT-treatment (F15 + W100\%), and soil in S-6 under unfrozen condition. $R^{2}$ for the $\mathrm{Pb}$ Weber-Morris model ranged from 0.02 to 0.92 . Soils in S-4 and S-3 did not fit well in some conditions. Compared to the control with no FT-treatment, the $Q_{e}$ value was higher at $25.41 \pm 2.76$ under 15 FTCs and $100 \%$ water content in soil of $\mathrm{S}-1$, while the $Q_{e}$ value for the FT-treatment $(\mathrm{F} 15+\mathrm{W} 60 \%)$ were lower at $20.46 \pm 2.96$. For the control with unfrozen soil, the $Q_{e}$ value was higher at $41.05 \pm 7.4$ in soils of $S-2$, while the $Q_{e}$ values for the FT-treatments (F15 + W60\% and $\mathrm{F} 15+\mathrm{W} 100 \%)$ were lower at $28.35 \pm 5.17$ and $35.53 \pm 4.69$, respectively. The soils in S-5 were similar to the soils of S-2 under the same FT-treatments; conversely, the $Q_{e}$ values in soils of S-3, S-4, and S-6 under FT-treatments increased compared to the control with no FT-treatment.

Equilibrium of adsorption of $\mathrm{Cr}$ ions was not achieved after $480 \mathrm{~min}$ for soil under unfrozen in S-5, $0.78 \mathrm{~h}$ for soil under 15 FTCs and $60 \%$ water content, and $0.51 \mathrm{~h}$ for soil under 15 FTCs and 100\% water content. Equilibrium of adsorption of $\mathrm{Cr}$ ions was achieved after $0.74 \mathrm{~h}$ for soil under 


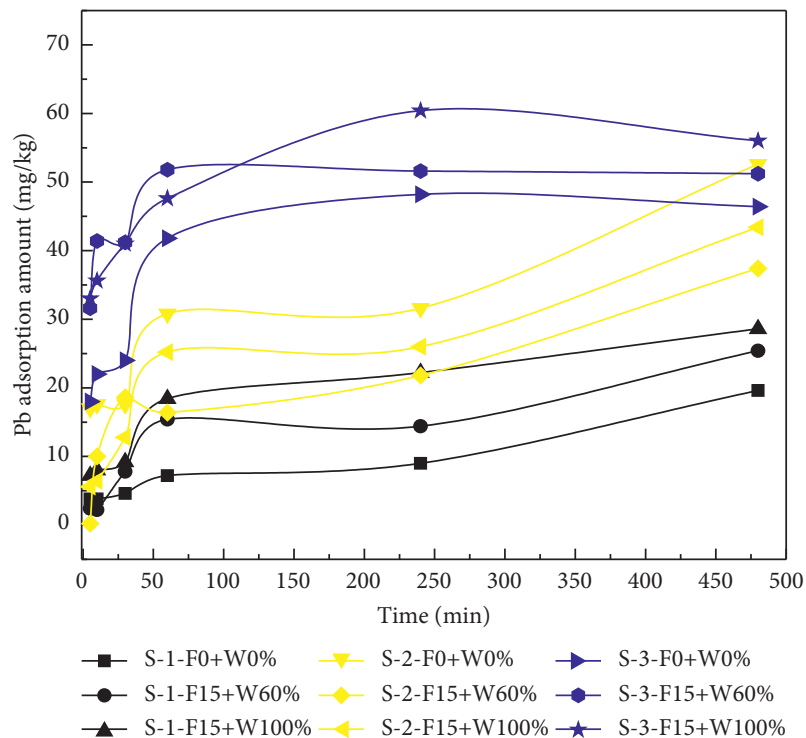

(a)

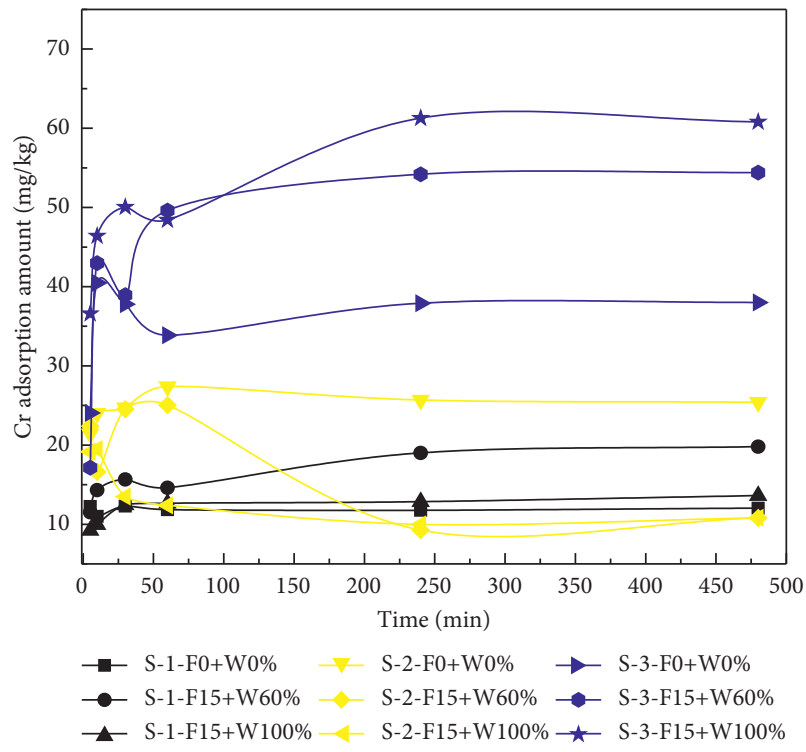

(c)

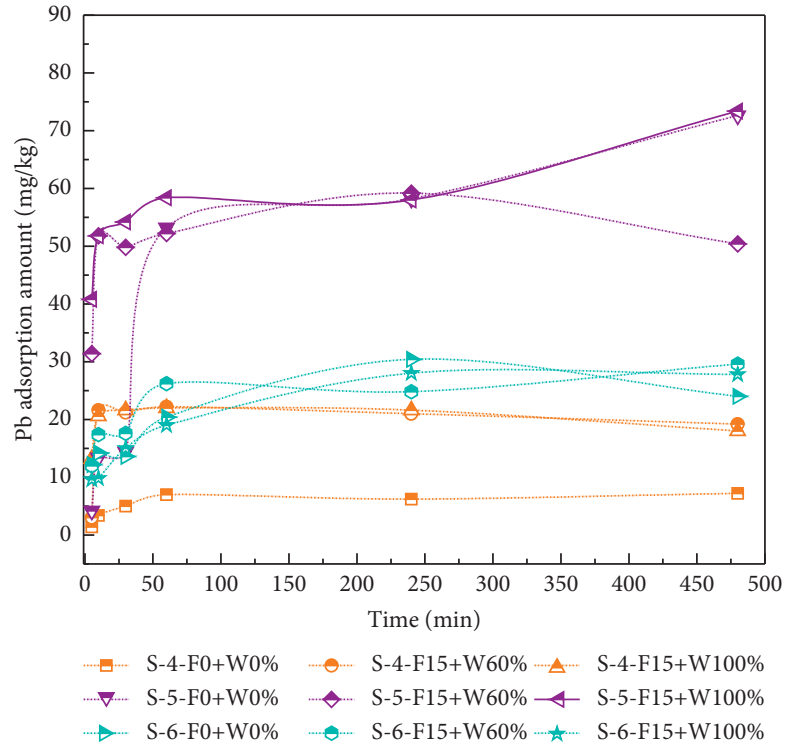

(b)

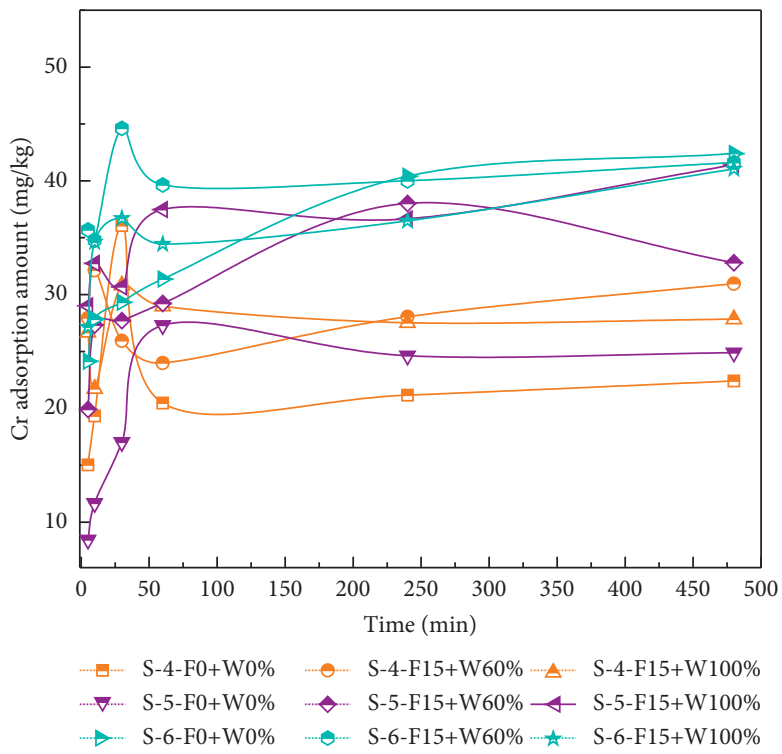

(d)

Figure 3: Adsorption amount of the $\mathrm{Pb}$ and $\mathrm{Cr}$ as a function of stirring time. $\mathrm{F} 0$ and $\mathrm{F} 15$ refer to the number of freeze-thaw cycles $(0$ and 15 cycles), and $\mathrm{W} 0 \%, \mathrm{~W} 60 \%$, and $\mathrm{W} 100 \%$ refer to water ratio of field capacity $(0 \%, 60 \%$, and $100 \%$ water ratio).

unfrozen in S-3, $0.14 \mathrm{~h}$ for soil under 15 FTCs and $60 \%$ water content, and $0.25 \mathrm{~h}$ for soil under 15 FTCs and $100 \%$ water content. The patterns of $\mathrm{Cr}$ adsorption in soil of S- 6 under different conditions were similar to the soils in S-4. These results demonstrated that the kinetics of $\mathrm{Pb}$ adsorption under FT-treatments were more rapid than the unfrozen soils. Conversely, equilibrium of adsorption of $\mathrm{Cr}$ ions was achieved after $0.56 \mathrm{~h}$ for soil under unfrozen in S-3, $1.23 \mathrm{~h}$ for soil under 15 FTCs and $60 \%$ water content, and $0.71 \mathrm{~h}$ for soil under 15 FTCs and 100\% water content. The results indicated that most $\mathrm{Cr}$ adsorption patterns on soils under freeze-thaw conditions were rapid than unfrozen conditions.

According to Table 4, parts of data could not be fitted using the pseudo-first-order model and Weber-Morris model. $R^{2}$ for the $\mathrm{Pb}$ pseudo-first-order model ranged from 0.001 to 0.91 . $R^{2}$ for the Cr Weber-Morris model ranged from 0.02 to 0.95 . Most of the $R^{2}$ data of the pseudo-firstorder model and Weber-Morris model were lower than 0.8 , the correlations were weak in most soil samplings under different conditions. For the control with no FT-treatment, the $Q_{e}$ value was lower at $37.63 \pm 1.84$ in soils of S-3, while the $Q_{e}$ values for the FT-treatments $(\mathrm{F} 15+\mathrm{W} 60 \%$ and $\mathrm{F} 15+\mathrm{W} 100 \%)$ were higher at $50.45 \pm 3.93$ and $55.03 \pm 2.98$, respectively. The soils in S-4, S-5, and S-6 were similar to the soils of S-3 under the same FT-treatments. The results indicated that most $\mathrm{Cr}$ adsorption amounts on soils under freeze-thaw conditions were higher than unfrozen conditions. 
TABle 3: Pseudo-first-order and Weber-Morris parameters of $\mathrm{Pb}$ in soils under different freeze-thaw conditions.

\begin{tabular}{|c|c|c|c|c|c|c|c|}
\hline \multirow{2}{*}{ Site area } & \multirow{2}{*}{ FTCs } & \multicolumn{3}{|c|}{$\mathrm{Pb}$ (pseudo-first-order kinetics) } & \multicolumn{3}{|c|}{$\mathrm{Pb}$ (Weber-Morris) } \\
\hline & & $Q_{e}$ & $k$ & $r^{2}$ & C & $k$ & $r^{2}$ \\
\hline \multirow{3}{*}{ S-1 } & $\mathrm{F} 0+\mathrm{W} 0 \%$ & $22.95 \pm 13.13$ & $0.19 \pm 0.21$ & 0.72 & $1.13 \pm 1.49355$ & $5.69 \pm 0.98$ & 0.89 \\
\hline & F15 + W60\% & $20.46 \pm 2.96$ & $1.08 \pm 0.49$ & 0.84 & $1.28 \pm 2.49$ & $8.27 \pm 1.64$ & 0.86 \\
\hline & $\mathrm{F} 15+\mathrm{W} 100 \%$ & $25.41 \pm 2.76$ & $1.27 \pm 0.43$ & 0.84 & $5.36 \pm 1.75$ & $8.48 \pm 1.15$ & 0.93 \\
\hline \multirow{3}{*}{ S-2 } & $\mathrm{F} 0+\mathrm{W} 0 \%$ & $41.05 \pm 7.4$ & $1.69 \pm 0.99$ & 0.52 & $12.11 \pm 3.43$ & $13.07 \pm 2.26$ & 0.89 \\
\hline & $\mathrm{F} 15+\mathrm{W} 60 \%$ & $28.35 \pm 5.17$ & $1.42048 \pm 0.82$ & 0.72 & $3.69 \pm 3.71$ & $11.37 \pm 2.45$ & 0.84 \\
\hline & $\mathrm{F} 15+\mathrm{W} 100 \%$ & $35.53 \pm 4.69$ & $1.05 \pm 0.43$ & 0.85 & $3.29 \pm 3.37$ & $13.77 \pm 2.22$ & 0.90 \\
\hline \multirow{3}{*}{ S-3 } & $\mathrm{F} 0+\mathrm{W} 0 \%$ & $45.79 \pm 4.73$ & $2.55 \pm 0.95$ & 0.76 & $19.26 \pm 5.02$ & $11.72 \pm 3.31$ & 0.75 \\
\hline & $\mathrm{F} 15+\mathrm{W} 60 \%$ & $48.96 \pm 2.22$ & $11.84 \pm 2.66$ & 0.76 & $37.38 \pm 4.05$ & $6.15 \pm 2.67$ & 0.56 \\
\hline & $\mathrm{F} 15+\mathrm{W} 100 \%$ & $51.23 \pm 4.15$ & $9.22 \pm 3.39$ & 0.56 & $33.61 \pm 3.59$ & $9.94 \pm 2.37$ & 0.81 \\
\hline \multirow{3}{*}{ S-4 } & $\mathrm{F} 0+\mathrm{W} 0 \%$ & $6.78 \pm 0.35$ & $3.34 \pm 0.66$ & 0.94 & $2.95 \pm 1.10$ & $1.72 \pm 0.73$ & 0.58 \\
\hline & $\mathrm{F} 15+\mathrm{W} 60 \%$ & $21.35 \pm 2.53$ & $7.49 \pm 3.86$ & 0.65 & $14.97 \pm 5.27$ & $2.53 \pm 3.48$ & 0.11 \\
\hline & $\mathrm{F} 15+\mathrm{W} 100 \%$ & $21.00 \pm 0.95$ & $13.72 \pm 3.32$ & 0.74 & $18.88 \pm 2.54$ & $0.51 \pm 1.68$ & 0.02 \\
\hline \multirow{3}{*}{ S-5 } & $\mathrm{F} 0+\mathrm{W} 0 \%$ & $67.23 \pm 7.16$ & $1.00 \pm 0.33$ & 0.91 & $4.51 \pm 8.82$ & $26.12 \pm 5.82$ & 0.83 \\
\hline & $\mathrm{F} 15+\mathrm{W} 60 \%$ & $53.46 \pm 2.37$ & $12.57 \pm 2.84$ & 0.78 & $43.57 \pm 6.10$ & $4.61 \pm 4.03$ & 0.24 \\
\hline & $\mathrm{F} 15+\mathrm{W} 100 \%$ & $60.90 \pm 3.66$ & $12.54 \pm 3.83$ & 0.61 & $44.71 \pm 3.62$ & $9.44 \pm 2.39$ & 0.79 \\
\hline \multirow{3}{*}{ S-6 } & $\mathrm{F} 0+\mathrm{W} 0 \%$ & $23.95 \pm 3.45$ & $4.01 \pm 2.32$ & 0.46 & $12.03 \pm 3.03$ & $5.88 \pm 2.00$ & 0.68 \\
\hline & $\mathrm{F} 15+\mathrm{W} 60 \%$ & $25.21 \pm 2.19$ & $6.34 \pm 2.34$ & 0.69 & $14.38 \pm 2.53$ & $5.70 \pm 1.67$ & 0.74 \\
\hline & $\mathrm{F} 15+\mathrm{W} 100 \%$ & $26.94 \pm 2.60$ & $1.79 \pm 0.57$ & 0.83 & $8.76 \pm 2.00$ & $7.82 \pm 1.32$ & 0.89 \\
\hline
\end{tabular}

Note. F0 and F15 refer to the number of freeze-thaw cycles ( 0 and 15 cycles), and W0\%, W60\%, and W $100 \%$ refer to water ratio of field capacity $(0 \%$, $60 \%$, and $100 \%$ water ratio).

TABle 4: Pseudo-first-order and Weber-Morris parameters of $\mathrm{Cr}$ in soils under different freeze-thaw conditions.

\begin{tabular}{|c|c|c|c|c|c|c|c|}
\hline \multirow{2}{*}{ Site area } & \multirow{2}{*}{ FTCs } & \multicolumn{3}{|c|}{$\mathrm{Cr}$ (pseudo-first-order kinetics) } & \multicolumn{3}{|c|}{ Cr (Weber-Morris) } \\
\hline & & $Q_{e}$ & $k$ & $r^{2}$ & C & $k$ & $r^{2}$ \\
\hline \multirow{3}{*}{ S-1 } & $\mathrm{F} 0+\mathrm{W} 0 \%$ & - & - & - & $11.77 \pm 0.35$ & $0.06 \pm 0.23$ & 0.02 \\
\hline & $\mathrm{F} 15+\mathrm{W} 60 \%$ & $17.21 \pm 1.10$ & $12.19 \pm 3.92$ & 0.59 & $12.34692 \pm 0.87042$ & $2.87 \pm 0.57$ & 0.86 \\
\hline & $\mathrm{F} 15+\mathrm{W} 100 \%$ & $12.75 \pm 0.44$ & $12.71 \pm 2.27$ & 0.79 & $10.08 \pm 0.78$ & $1.41 \pm 0.52$ & 0.64 \\
\hline \multirow{3}{*}{$S-2$} & $\mathrm{~F} 0+\mathrm{W} 0 \%$ & $25.64 \pm 0.51$ & $20.82 \pm 3.08$ & 0.76 & $23.58 \pm 1.30$ & $0.97 \pm 0.86$ & 0.24 \\
\hline & $\mathrm{F} 15+\mathrm{W} 60 \%$ & - & - & - & $24.39 \pm 3.45$ & $-5.21 \pm 2.28$ & 0.56 \\
\hline & $\mathrm{F} 15+\mathrm{W} 100 \%$ & - & - & - & $18.26 \pm 1.81$ & $-3.35 \pm 1.19$ & 0.66 \\
\hline \multirow{3}{*}{$S-3$} & $\mathrm{~F} 0+\mathrm{W} 0 \%$ & $37.63 \pm 1.84$ & $15.42 \pm 4.33$ & 0.67 & $32.54 \pm 4.10$ & $2.32 \pm 2.71$ & 0.15 \\
\hline & $\mathrm{F} 15+\mathrm{W} 60 \%$ & $50.45 \pm 3.93$ & $7.16 \pm 2.41$ & 0.77217 & $30.47 \pm 7.16$ & $10.28 \pm 4.73$ & 0.54 \\
\hline & $\mathrm{F} 15+\mathrm{W} 100 \%$ & $55.03 \pm 2.98$ & $12.31 \pm 3.35$ & 0.67056 & $40.54 \pm 3.14$ & $8.33 \pm 2.07$ & 0.80 \\
\hline \multirow{3}{*}{ S-4 } & $\mathrm{F} 0+\mathrm{W} 0 \%$ & $24.80 \pm 3.26$ & $10.75 \pm 6.74$ & 0.33883 & - & - & - \\
\hline & $\mathrm{F} 15+\mathrm{W} 60 \%$ & $28.20 \pm 1.52$ & $59.07 \pm 220.48$ & 0.001 & $27.34 \pm 2.23$ & $0.68 \pm 1.47$ & 0.05 \\
\hline & $\mathrm{F} 15+\mathrm{W} 100 \%$ & $27.50 \pm 1.55$ & $35.73 \pm 32.36$ & 0.0172 & $0.78 \pm 1.47$ & $26.30 \pm 2.23$ & 0.06 \\
\hline \multirow{3}{*}{ S-5 } & $\mathrm{F} 0+\mathrm{W} 0 \%$ & $25.21 \pm 1.60$ & $3.36 \pm 0.82$ & 0.91004 & $12.08 \pm 3.98$ & $5.72 \pm 2.63$ & 0.54 \\
\hline & $\mathrm{F} 15+\mathrm{W} 60 \%$ & $32.00 \pm 1.96$ & $11.48 \pm 3.45$ & 0.66061 & $23.50 \pm 2.86$ & $4.69 \pm 1.89$ & 0.60 \\
\hline & $\mathrm{F} 15+\mathrm{W} 100 \%$ & $36.29 \pm 1.91$ & $18.04 \pm 6.11$ & 0.42226 & $29.72 \pm 1.65$ & $4.10 \pm 1.09$ & 0.77 \\
\hline \multirow{3}{*}{ S-6 } & $\mathrm{F} 0+\mathrm{W} 0 \%$ & $35.72 \pm 2.92$ & $11.36 \pm 4.52$ & 0.48214 & $24.06 \pm 1.18$ & $7.06 \pm 0.78$ & 0.95311 \\
\hline & $\mathrm{F} 15+\mathrm{W} 60 \%$ & $40.61 \pm 1.56$ & $22.07 \pm 6.64$ & 0.35317 & $37.35 \pm 2.46$ & $1.68 \pm 1.62$ & 0.21163 \\
\hline & $\mathrm{F} 15+\mathrm{W} 100 \%$ & $37.18 \pm 1.17$ & $15.77 \pm 2.89$ & 0.77708 & $30.81 \pm 2.16$ & $3.52 \pm 1.42$ & 0.60374 \\
\hline
\end{tabular}

Note. "-" means that these data could not be fitted using the pseudo-first-order and Weber-Morris models. F0 and F15 refer to the number of freeze-thaw cycles ( 0 and 15 cycles), and W0\%, W60\%, and $\mathrm{W} 100 \%$ refer to water ratio of field capacity $(0 \%, 60 \%$, and $100 \%$ water ratio).

\section{Conclusions}

Results showed that different FT-treatments and soil water content affected the lead and chromium immobilization process in the northeastern Qinghai-Tibet Plateau. The different soil adsorption trends of $\mathrm{Pb}$ and $\mathrm{Cr}$ responded more or less constantly with change in the water-soil ratios. The $\mathrm{Pb}$ and $\mathrm{Cr}$ adsorption amount mostly decreased with increasing the water-soil ratio, and the soil performance of
$\mathrm{Pb}$ and $\mathrm{Cr}$ adsorption at the same water-soil ratios showed variation under different freeze-thaw conditions. The adsorption of $\mathrm{Pb}$ was higher for most FT-treatments compared to the control. The soil performance of $\mathrm{Cr}$ isothermal adsorption showed variation under different freeze-thaw conditions. Most electrostatic binding of $\mathrm{Pb}$ and $\mathrm{Cr}$ was stronger under unfrozen and freeze-thaw conditions than unfrozen conditions. Most $\mathrm{Pb}$ adsorption kinetics patterns of FT-treated soils were rapid than unfrozen conditions; the 
$Q_{e}$ values in soils of S-3, S-4, and S-6 under FT-treatments increased compared to the control with no FT-treatment. Most $\mathrm{Cr}$ adsorption kinetics patterns on soils under freezethaw conditions were rapid than unfrozen conditions, and most $\mathrm{Cr}$ adsorption amounts on soils under freeze-thaw conditions were higher than unfrozen conditions. These results implied that FT-treatment could change the soil adsorption and desorption patterns of $\mathrm{Pb}$ and $\mathrm{Cr}$. Therefore, further studies are urgently needed to investigate the lead and chromium immobilization mechanism of heavy metals in soils during FTCs.

\section{Data Availability}

The data are available on request.

\section{Conflicts of Interest}

No potential conflicts of interest are reported by the authors.

\section{Acknowledgments}

This work was supported by Natural Science Foundation of Qinghai Province (2019-ZJ-909), Youth Innovation Team Project for Talent Introduction and Cultivation in Universities of Shandong Province, Two Hundred Talents Plan of Yantai, and Thousand Talents Plan of Qinghai Province.

\section{References}

[1] Y. Ran, X. Li, G. Cheng et al., "Distribution of permafrost in China: an overview of existing permafrost maps," Permafrost and Periglacial Processes, vol. 23, no. 4, pp. 322-333, 2012.

[2] D. Dagesse, "Effect of freeze-drying on soil aggregate stability," Soil Science Society of America Journal, vol. 75, no. 6, pp. 2111-2121, 2011.

[3] X. Dang, Y. Zhang, N. Yu, and Y. Zhang, "Cadmium adsorption-desorption of brown soil with freeze-thaw cycles in northeast China," International Journal of Environment and Pollution, vol. 49, no. 1/2, pp. 89-99, 2012.

[4] Y. Liu, Q. Wang, S. Liu et al., "Experimental investigation of the geotechnical properties and microstructure of lime-stabilized saline soils under freeze-thaw cycling," Cold Regions Science and Technology, vol. 161, pp. 32-42, 2019.

[5] R. Ma, Y. Jiang, B. Liu, and H. Fan, "Effects of pore structure characterized by synchrotron-based micro-computed tomography on aggregate stability of black soil under freezethaw cycles," Soil and Tillage Research, vol. 207, Article ID 104855, 2021.

[6] G.-Y. Li and H.-M. Fan, "Effect of freeze-thaw on water stability of aggregates in a black soil of northeast China," Pedosphere, vol. 24, no. 2, pp. 285-290, 2014.

[7] Z. Han, M. Deng, A. Yuan, J. Wang, H. Li, and J. Ma, "Vertical variation of a black soil's properties in response to freeze-thaw cycles and its links to shift of microbial community structure," The Science of the Total Environment, vol. 625, pp. 106-113, 2018.

[8] H. T. Koponen and E. Bååth, "Soil bacterial growth after a freezing/thawing event," Soil Biology and Biochemistry, vol. 100, pp. 229-232, 2016.

[9] P. O. Sorensen, A. C. Finzi, M.-A. Giasson, A. B. Reinmann, R. Sanders-DeMott, and P. H. Templer, "Winter soil freeze- thaw cycles lead to reductions in soil microbial biomass and activity not compensated for by soil warming," Soil Biology and Biochemistry, vol. 116, pp. 39-47, 2018.

[10] T. Watanabe, R. Tateno, S. Imada et al., "The effect of a freezethaw cycle on dissolved nitrogen dynamics and its relation to dissolved organic matter and soil microbial biomass in the soil of a northern hardwood forest," Biogeochemistry, vol. 142, no. 3, pp. 319-338, 2019.

[11] J. Liu, F. Wu, W. Yang et al., "Effect of seasonal freeze-thaw cycle on net nitrogen mineralization of soil organic layer in the subalpine/alpine forests of western Sichuan, China," Acta Ecologica Sinica, vol. 33, no. 1, pp. 32-37, 2013.

[12] C. B. Fuss, C. T. Driscoll, P. M. Groffman et al., "Nitrate and dissolved organic carbon mobilization in response to soil freezing variability," Biogeochemistry, vol. 131, no. 1-2, pp. 35-47, 2016.

[13] P. Grogan, A. Michelsen, P. Ambus, and S. Jonasson, "Freezethaw regime effects on carbon and nitrogen dynamics in subarctic heath tundra mesocosms," Soil Biology and Biochemistry, vol. 36, no. 4, pp. 641-654, 2004.

[14] D. A. Lipson, S. K. Schmidt, and R. K. Monson, "Carbon availability and temperature control the post-snowmelt decline in alpine soil microbial biomass," Soil Biology and Biochemistry, vol. 32, no. 4, pp. 441-448, 2000.

[15] J. P. Winter, Z. Zhang, M. Tenuta, and R. P. Voroney, "Measurement of microbial biomass by fumigation-extraction in soil stored frozen," Soil Science Society of America Journal, vol. 58, no. 6, pp. 1645-1651, 1994.

[16] Z. Shabbir, A. Sardar, A. Shabbir et al., "Copper uptake, essentiality, toxicity, detoxification and risk assessment in soil-plant environment," Chemosphere, vol. 259, Article ID 127436, 2020.

[17] M. Mokarram, H. R. Pourghasemi, and H. Zhang, "Predicting non-carcinogenic hazard quotients of heavy metals in pepper (Capsicum annum L.) utilizing electromagnetic waves," Frontiers of Environmental Science and Engineering, vol. 14, no. 6, p. 114, 2020.

[18] W. Li and J. D. Fortner, "(Super) paramagnetic nanoparticles as platform materials for environmental applications: from synthesis to demonstration," Frontiers of Environmental Science \& Engineering, vol. 14, no. 5, p. 77, 2020.

[19] J. Lu, Y. Lin, J. Wu, and C. Zhang, "Continental-scale spatial distribution, sources, and health risks of heavy metals in seafood: challenge for the water-food-energy nexus sustainability in coastal regions," Environmental Science and Pollution Research, 2020.

[20] K. M. Sta Ana and M. P. Espino, "Occurrence and distribution of hormones and bisphenol A in Laguna lake, Philippines," Chemosphere, vol. 256, Article ID 127122, 2020.

[21] B. Lv, Y. Cui, W. Tian et al., "Vessel transport of antibiotic resistance genes across oceans and its implications for ballast water management," Chemosphere, vol. 253, Article ID 126697, 2020.

[22] P. Kovalakova, L. Cizmas, M. Feng, T. J. McDonald, B. Marsalek, and V. K. Sharma, "Oxidation of antibiotics by ferrate(VI) in water: evaluation of their removal efficiency and toxicity changes," Chemosphere, vol. 277, Article ID 130365, 2021.

[23] D. Payandi-Rolland, L. S. Shirokova, F. Labonne, P. Bénézeth, and O. S. Pokrovsky, "Impact of freeze-thaw cycles on organic carbon and metals in waters of permafrost peatlands," Chemosphere, vol. 279, Article ID 130510, 2021.

[24] R. M. Nagare, R. A. Schincariol, W. L. Quinton, and M. Hayashi, "Effects of freezing on soil temperature, freezing 
front propagation and moisture redistribution in peat: laboratory investigations," Hydrology and Earth System Sciences, vol. 16, no. 2, pp. 501-515, 2012.

[25] F. Wang, W. Ouyang, F. Hao, W. Jiao, Y. Shan, and C. Lin, "Role of freeze-thaw cycles and chlorpyrifos insecticide use on diffuse Cd loss and sediment accumulation," Scientific Reports, vol. 6, no. 1, Article ID 27302, 2016.

[26] R. Hou, L. Wang, D. O’Connor, D. C. W. Tsang, J. Rinklebe, and D. Hou, "Effect of immobilizing reagents on soil Cd and $\mathrm{Pb}$ lability under freeze-thaw cycles: implications for sustainable agricultural management in seasonally frozen land," Environment International, vol. 144, Article ID 106040, 2020.

[27] L. Li, J. Ma, M. Xu et al., "The adsorption and desorption of $\mathrm{Pb}^{2+}$ and $\mathrm{Cd}^{2+}$ in freeze-thaw treated soils," Bulletin of Environmental Contamination and Toxicology, vol. 96, no. 1, pp. 107-112, 2016.

[28] X. Wang, Y. Li, N. Mao, Y. Zhou, and P. Guo, "The adsorption behavior of $\mathrm{Pb}^{2+}$ and $\mathrm{Cd}^{2+}$ in the treated black soils with different freeze-thaw frequencies," Water, Air, and Soil Pollution, vol. 228, no. 5, pp. 193-199, 2017.

[29] J. N. Quinton and J. A. Catt, "Enrichment of heavy metals in sediment resulting from soil erosion on agricultural fields," Environmental Science and Technology, vol. 41, no. 10, pp. 3495-3500, 2007.

[30] S. An, F. Zhang, X. Chen et al., "Effects of freeze-thaw cycles on distribution and speciation of heavy metals in pig manure," Environmental Science and Pollution Research, vol. 27, no. 8, pp. 8082-8090, 2020.

[31] A. M. McIntyre and C. Guéguen, "Binding interactions of algal-derived dissolved organic matter with metal ions," Chemosphere, vol. 90, no. 2, pp. 620-626, 2013.

[32] L. Ming, L. Li, Y. Zhang et al., "Effects of dissolved organic matter on the desorption of $\mathrm{Cd}$ in freeze-thaw treated $\mathrm{Cd}$ contaminated soils," Chemistry and Ecology, vol. 30, no. 1, pp. 76-86, 2014.

[33] L. Du, M. Dyck, W. Shotyk et al., "Lead immobilization processes in soils subjected to freeze-thaw cycles," Ecotoxicology and Environmental Safety, vol. 192, Article ID 110288 , 2020.

[34] M. K. Moftakhar, M. R. Yaftian, and M. Ghorbanloo, “Adsorption efficiency, thermodynamics and kinetics of Schiff base-modified nanoparticles for removal of heavy metals," International Journal of Environmental Science and Technology, vol. 13, no. 7, pp. 1707-1722, 2016.

[35] G. Sposito, "Derivation of the Freundlich equation for ion exchange reactions in soils," Soil Science Society of America Journal, vol. 44, no. 3, pp. 652-654, 1980. 